\section{HEAD INJURY: ORGANIZATIONAL ASPECTS OF CARE}

Corrado Manni, M.D., F. Della Corte, M.D. and A. Proietti, M.D., Rome, Italy

Head injury still accounts for $1 \%$ of the deaths in Italy and a larger percentage of severe disability. Thus, the technological, organizative, economical and therapeutical efforts appear truly justifiable. The best outcome results can be obtained by instituting the following: 1) Continuous and appropriate information to the general population about rescue and first aid; 2) The most immediate intervention at the site with an appropriate means of rescue; 3) Experienced general and medical assistants; 4) Ability to carry out instrumental and pharmacological therapies aimed at maintaining vital functions during transportation; 5) Uniformity and simplicity in exchanging information; 6) Selection of the most appropriate hospital.

\section{ENDOTOXIN BLUNTS THE CHRONOTROPIC RESPONSE TO ISOPROTERENOL IN THE DOG MODEL}

Thomas J. Iberti, M.D., David R. Gentili, M.D.,

Saul R. Berger, M.D., Thomas A. Paluch, M.D., Ernest Benjamin, M.D., New York, New York, U.S.A.

Previous studies have demonstrated myocardial depression associated with endotoxemia. In addition, we recently described a significantly slower heart rate (HR) seen in canine endotoxic shock than that observed with hemorrhagic shock of similar severity. The purpose of this study was to examine the chronotropic effects of isoproterenol (ISO) in endotoxic dogs to determine if the negative chronotropy seen in endotoxemia could be eliminated by beta agonist therapy. Eighteen dogs were anesthetized, ventilated and hemodynamically monitored. After stabilization, they were randomized to 3 groups. Group I received isoproterenol $0.1 \mathrm{mg} / \mathrm{kg} / \mathrm{min}$; Group II $4 \mathrm{mg} / \mathrm{kg} \mathrm{E}$. coli endotoxin (ENDO); and Group III received both ISO and ENDO.

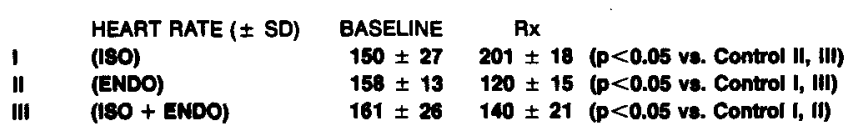

The results of this study demonstrate that the chronotropic effects of ISO are depressed in the presence of endotoxin. Thus, in the endotoxic animal model, beta adrenergic stimuli does not overcome the negative chronotropic response to endotoxin. The pathophysiology of this phenomenon remains to be defined, but may involve nodal ischemia, diffuse myocardial depression, or direct action of endotoxin.

\section{EMERGENCY MANAGEMENT OF PENETRATING MISSILE HEAD INJURIES}

\section{A.A. Ameen, M.D., Basrah, Iraq}

The experience of the neurosurgical unit at Basrah General Teaching Hospital (Iraq) during the 6 years period of the Iraqui Iranian War in the treatment of penetrating craniocerebral injuries is reported, with particular reference to the triage and management of large combat casualties received during busy periods that follow a major battle or bombardment of the city.

Attention is drawn also to the diagnostic difficulties that occur in assessing patients with head and associated injuries. The role of CAT scanning in the immediate management is discussed, as compared to other studies in the pre-CAT scanner era.

\section{TRAINING, TEACHING, ORGANIZATION AND MANAGEMENT OF TRAUMA IN AN URBAN SETTING

\author{
Ayuyao Adolfom, M.D., New York, \\ New York, U.S.A.
}

Much has been written about the training of a surgeon, the proper qualifications, and what it means to be a surgeon. However, there has been no emphasis given to the important topic of trauma. A training surgical resident rotates through different surgical divisions and subspecialties, but seldom will you find a rotation in an organized trauma service.

Providing care to the injured was one of the earliest recorded roles of a surgeon. However, this aspect of medicine has not been emphasized in most training programs while other areas of surgery have been favored. It is only in the past few decades that attention has been focused on the care of the injured. The 